GLOSSARY

\title{
International cooperation and health. Part 2: making a difference
}

Martin McKee, Anna B Gilmore, Nina Schwalbe

J Epidemiol Community Health 2005;59:737-739. doi: 10.1136/jech.2004.027854

The world is increasingly shaped by powerful global forces, many of which have consequences for human health and the social, economic, and environmental factors that influence health are increasingly determined at a supranational level. As a result, local or national level efforts to influence health determinants can have only a limited impact and it is all too easy for the individual public health practitioner to feel powerless. Yet while public health practitioners, on their own, may indeed be relatively powerless, together they can achieve a great deal. Part 2 of this glossary explores some of the strategies that they can use as they seek to make a difference.

See end of article for authors' affiliations

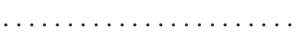

Correspondence to: Professor M McKee,

European Centre on Health of Societies in Transition, London School of Hygiene and Tropical Medicine, Keppel Street, London WCIE 7HT, UK; martin.mckee@|shtm. ac.uk

Accepted for publication 4 August 2004
$\mathrm{T}$ he first part of this glossary described selected issues and concepts from the area of international health. ${ }^{1}$ This part addresses the contribution that can be made by the many individuals and organisations whose common aim is to make the world a better place. In many cases their primary interest is not in health, but rather in areas such as peace, human rights, or the environment. However, success in these areas will do much to promote sustainable population health. Their ability to bring about change in the global arena provides lessons for public health as well as showing the scope to develop strategic alliances.

\section{ADVOCACY}

Public health advocacy has been described as the strategic use of news media to advance a public policy initiative often in the face of major opposition. ${ }^{2}$ It aims to change policies, laws, standards, and funding rather than individual behaviour. Advocacy can and has achieved a great deal $^{3}$ and could therefore claim to be a fundamental part of public health practice, yet it remains a neglected discipline rarely addressed in the public health literature or training programmes and although seen as a key area of action by some public health associations, ${ }^{4}$ it is ignored by others.

As the tobacco transnational $\mathrm{R} J$ Reynolds noted in 1996 when stating: "[t]he Advocacy Institute was probably the key factor in changing the anti-smokers from a group of individual organizations into a tightly knit, well-coordinated movement", advocacy efforts can be increased through improved cooperation. As policy debates move from the national to supranational arenas the need for international cooperation in advocacy has become paramount. An early example was Infact's Nestlé Boycott in the 1970s and 1980s in response to infant formula marketing. This ultimately involved over 10 countries, brought worldwide condemnation of Nestlés practices and effected the passage of the WHO's International Code of Marketing for Breast Milk Substitutes. More recently there has been a growth in global advocacy networks such as Climate Action Network, a grouping of over 287 non-governmental organisations (NGOs) established in 1989 to influence the climate negotiations, climate related policies, and measures at national and international levels, ${ }^{6}$ and the Framework Convention Alliance, a similar group aiming to support the development and ratification of an effective Framework Convention on Tobacco Control. ${ }^{7}$ The growth in communication technologies (see global information management) is key to the success of such efforts.

\section{CULTURE JAMMING}

The relentless expansion of the tobacco epidemic has been fuelled by the transnational tobacco companies ability to tap into the global spread of ideas and beliefs propagated via the mass media (in what has become known as cognitive globalisation) in creating global brands and a "global smoker". ${ }^{8}$ The global spread of "junk foods" can be attributed to the same processes. Culture jamming is a response to this spread of a homogenous global culture dominated by large corporations. It includes activities designed to challenge the way in which our lives are shaped by the marketing industry, tackling issues such as the saturation of open space by advertising, and constraints on choice, such as the exclusive deals between soft drinks companies and schools that prevent access by children to other products or even drinking fountains. One particular version, known as sniggles, ${ }^{10}$ are pranks or hoaxes designed to satirise or ridicule those in authority. Although the motives behind sniggles vary widely, this approach is increasingly being adopted to parody the messages being promoted by global corporations and other powerful interests. The web site of the Canadian organisation Adbusters provides numerous examples of how corporations are using advertising to promote unhealthy products and ways to challenge them. ${ }^{11}$

\section{DIRECT ACTION}

The term direct action refers to anything that a person or group does that directly affects those promoting, implementing, or suffering from a 
particular policy. Thus, in the present context, it spans a spectrum from volunteering one's skills to help others (for example, those working for organisations such as Médecins sans Frontières) to withdrawing cooperation with activities damaging to health (for example, refusing to serve in the armed forces) or taking action against harm producing activities (for example, staging protests to block road building or the conveyance of nuclear waste). Direct action to promote health has often adopted highly imaginative approaches, for example the Australian BUGA-UP (billboard utilising graffitists against unhealthy promotions) campaign, in which activists used spray paint to twist the messages on hoardings advertising cigarettes against the tobacco industry. ${ }^{12}$

\section{DOCUMENTARY RESEARCH}

We have made reference above to the tobacco industry's misdemeanours, ${ }^{13}$ and its monitoring of health activists. ${ }^{5}$ This information stems from the analysis of previously secret tobacco industry documents, initially provided by whistleblowers and later as a result of litigation in the USA. ${ }^{14}$ Researchers have also used similar methods to investigate the petroleum, chemical, and other industries ${ }^{15}$ and as litigation of other industries is contemplated, other documents may become available. Meanwhile analysis of the tobacco industry documents provides insights into corporate behaviour and the way in which document analysis can be used to further public health.

The tobacco industry documents have provided a unique insight into the conduct of the primary vectors of the tobacco pandemic, the transnational tobacco companies, exposing the cynical discrepancy between their public denial of the health impacts and addictive nature of smoking and their private acknowledgement of these facts, the manipulation of cigarettes to increase their addictiveness, targeted marketing of cigarettes to vulnerable populations, covert efforts to undermine and repel tobacco control, and industry involvement in cigarette smuggling. ${ }^{16-18}$ In so doing the documents present a unique resource to public health, highlighting the tobacco control measures the industry most fears and legitimising the need for and improving understanding of the processes required to ensure effective tobacco control, in part by changing public attitudes to the industry.

\section{THE GLOBAL FUND FOR AIDS, TB, AND MALARIA}

The Global Fund has proved a ground breaking experiment in pooled funding and decision making for resource allocation in international health. Each donor contributes to a resource pool, governed by a board comprised of civil society, donors, and recipient country representatives. Unlike bilateral funding mechanisms, countries apply for funding in a competitive grant process reviewed by an independent technical review panel. The country proposals must be submitted by national coordinating mechanism, comprising government, civil society, and the private sector. Once grants have been given, their continuation depends on objective indicators of progress towards defined targets. The Global Fund is unusual in its explicit involvement of civil society (although Unicef provides another example). It has, however, faced difficulties in building the required models of cooperation in some countries. ${ }^{19}$ It has also received only limited support from one potentially major donor, the USA, which has been reluctant to surrender the influence it has over other forms of development assistance. In particular it is concerned about its inability to protect the American pharmaceutical industry and its promotion of ideologically driven but ineffective policies based on sexual abstinence.

\section{HEALTH PROFESSIONALS AND HUMAN RIGHTS}

Health professionals have not always promoted human rights and the experimentation by Nazi physicians on concentration camp inmates is well known. These experiments led to the Nuremburg Code on medical ethics and later to the Helsinki Declaration, although even now, in some countries health professionals continue to participate in torture and executions. However, health professionals have also contributed very positively. Perhaps the best known example is the International Physicians for the Prevention of Nuclear War, ${ }^{20}$ awarded the 1985 Nobel Prize for its contribution to disarmament and world peace. Other examples are Physicians for Human Rights, an American NGO, ${ }^{21}$ and the British organisation MEDACT. ${ }^{22}$ Physicians for Human Rights has investigated and campaigned against torture, disappearances, political killings, and other violations of humanitarian law. It has also worked to improve conditions in prisons and exposed continuing examples of complicity by health professionals in abuses of human rights. MEDACT works on topics ranging from nuclear disarmament, environmental degradation, and the rights of refugees. It has been especially active in developing training materials for health professionals.

\section{PARTICIPATIVE ACTION RESEARCH}

This has developed in response to concerns about the way research agendas are often shaped by powerful interests and often fail to meet the needs of populations that are the subject of the research, and who stand to gain or lose as a result of its findings. It has developed from concepts of lay epidemiology $^{23}$ or popular epidemiology, the latter being described as "the process by which persons gather statistics and other information and also direct and marshal the knowledge and resources of experts in order to understand the epidemiology of diseases". ${ }^{24}$ The research questions are developed by communities, based on their concerns, and influenced by their knowledge of the context in which the questions have arisen. The methods used draw on a range of disciplines and the key feature is the emphasis on research to improve practice rather than simply to produce knowledge. It provides an opportunity for ordinary people to reclaim the research agenda.

\section{PEOPLE'S HEALTH ASSEMBLY}

The first people's health assembly took place in India in December 2000, organised by international organisations, civil society groups, NGOs, and women's groups seeking to promote the principle of "Health for All" and to advocate greater implementation of the Alma Ata Declaration with its principles of primary health care and "people's perspective". The primary objective of the assembly was to "give voice to the people and make their voices heard in decisions affecting their health and well being." ${ }^{25}$ About 1500 people from 92 countries attended, adopting a People's Charter for Health. The charter focuses on health as a human right and calls for changes to the political, social, economic, and environmental frameworks and has been adopted as the guiding document for the People's Health Movement. The movement has developed into an international campaign to establish health equity in local, national, and international policy making. It focuses on the structural determinants of ill health, analysing inequity from the perspective of the excluded and the marginalised. It emphasises the need to shift the focus of blame for poor health from the person to the political systems that give rise to poor health outcomes, criticising multinational corporations, multilateral institutions, like the World Bank, and corrupt political systems, and maintains that the key determinants of health (basic and underlying factors and causes) are inequality and unequal distribution of wealth and resources. Both the forum and the People's 
Health Movement were designed as a counter balance to World Health Assembly, the governing body of the World Health Organisation in which only state actors have a voice and vote.

\section{SURVEILLANCE NETWORKS}

Communicable diseases do not respect national frontiers and the opportunities for them to spread globally have increased in parallel with the increasing intensity of global traffic, as illustrated by the rapid global spread of SARS from southern China in 2003. Public health professionals in many countries have joined together to form networks for the rapid exchange of information on outbreaks. Networks, focusing on a wide range of organisms and diseases, such as the European Working Group for Legionella Infections (EWGLI) or the European Influenza Surveillance Scheme (EISS), form the basis of international cooperation on communicable diseases within the European Union. ${ }^{26}$

\section{THIRD WORLD NETWORK}

The Third World Network is a network of organisations and institutions involved in issues related to development. It conducts and publishes research on economic, social, and environmental issues and provides a platform for discussion and presentation of this work. With a secretariat in Malaysia, it has offices in South Asia, South America, Europe, and Africa and affiliated organisations in countries throughout the world. The publications take a critical perspective on trade, biosafety, intellectual property, women's rights, UN, and global tourism, among other issues.

\section{WORLD HEALTH ORGANISATION}

The World Health Organisation is the lead agency of the United Nations in the field of health. Established in 1948, the WHO's stated objective is "attainment by all peoples of the highest possible level of health" (with health defined as a state of complete physical, mental, and social wellbeing and not merely the absence of disease or infirmity). The organisation is governed by 192 member states through the World Health Assembly, which is responsible for setting policy, approving programmes and budgets. Its accountability to its member states, some of which have not hesitated to exert inappropriate influence on the organisation, means that, despite the efforts of individual staff members, it has rarely been able to incorporate the views of civil society into its work to any significant extent. For example, the US government has recently required that the WHO, when seeking experts within the US government, should only indicate the general area of interest, leaving the selection of people to the US authorities. The WHO has also faced the problem of having to use official information supplied by its member states, regardless of its validity. As a consequence, it has often been seen as lacking independence, and thus credibility as it is unable to challenge erroneous information provided by governments determined to deny the existence of problems.

\section{WORLD SOCIAL FORUM}

The World Social Forum, first held in 2001, is a yearly gathering intended to provide a counterbalance to the World Economic Forum's Davos meeting. According to its charter of principles, the WSF is "an open meeting place for reflective thinking, democratic debate of ideas, formulation of proposals, free exchange of experiences, and inter-linking for effective action, by groups and movements of civil society that are opposed to neoliberalism and to domination of the world by capital and any form of imperialism." 27 In contrast with the gated and exclusive WEF meetings attended primarily by those who can afford the $\$ 25000$ membership fee, the WSF conference has drawn as many as 100000 participants and has provided a venue for activists to look at alternatives to market driven globalisation, specifically alternatives that emphasise human rights and social justice.

\section{ACKNOWLEDGEMENTS}

We are grateful to Allyson Pollock, Robert Beaglehole, Ronald Labonte, Kelley Lee, and an anonymous reviewer for comments on earlier drafts.

\section{Authors' affiliations}

M McKee, A B Gilmore, European Centre on Health of Societies in Transition, London School of Hygiene and Tropical Medicine, London, UK

N Schwalbe, Global Alliance for TB Drug Development, New York, USA

Funding: $A G$ is funded by the US National Institute of Health to work on tobacco industry documents.

Competing interests: MM is a member of the Open Society Institute's (OSI) public health sub-board and NS was the Director of the Public Health Program at OSI. OSI is committed to building open societies through collaboration between non-governmental organisations, governments, and international organisations. The views expressed cannot be taken as representing any of the organisations they are associated with.

\section{REFERENCES}

1 McKee M, Gilmore A, Schwalbe N. International cooperation and health. Part 1: issues and concepts. J Epidemiol Community Health 2005;59:628-31.

2 Chapman S. Advocacy for public health: a primer. J Epidemiol Community Health 2004;58:361-5.

3 Chapman S. Advocacy in public health: roles and challenges. Int J Epidemiol 2001;30:1226-32.

4 American Public Health Association. Legislation, advocacy and policy. http://www.apha.org/legislative/ (accessed 9 Feb 2003)

5 Reynolds RJ. Issues guide. November 1, 1996, Bates \#517523376-3640 http://legacy.library.ucsf.edu/tid/mkj82d00.

6 Climate Action network International. http://www.climatenetwork.org/ pages/AboutCANInt.html (accessed 1 Aug 2004).

7 Framework Convention Alliance. http://fctc.org/about_FCA/index.shtml (accessed 1 Aug 2004).

8 Bettcher D, Lee K. Globalisation and public health. J Epidemiol Community Health 2002;56:8-17

9 Collin J. Think global, smoke local: transnational tobacco companies and cognitive globalisation. In: Lee K, ed. Health impacts of globalization towards global governance. Basingstoke: Palgrave Macmillan, 2003.

10 Sniggles. http:// www.sniggle.net (accessed 1 Aug 2004).

11 Adbusters. http://adbusters.org/(accessed 1 Aug 2004).

12 BUGA UP. http://203.41.215.172/ (accessed 1 Aug 2004).

13 Barnes DE, Bero LA. Industry-funded research and conflict of interest: an analysis of research sponsored by the tobacco industry through the Center for Indoor Air Research. J Health Polit Policy Law 1996;21:515-42.

14 Rabin RL. The third wave of tobacco tort litigation. In: Rabin RL, SUgarman SD, eds. Regulating tobacco. New York: Oxford University Press, 2001.

15 Markowitz GE, Rosner D. Deceit and denial: the deadly politics of industrial pollution. Berkley, CA: University of California Press, 2002.

16 Lee K, Gilmore A, Collin J. Looking inside the tobacco industry: revealing insights from the Guildford Depository. Addiction 2004;99:394-7.

17 Bero L. Implications of the tobacco industry documents for public health and policy. Annu Rev Public Health 2003;24:267-88.

18 WHO Committee of Experts. Tobacco company strategies to undermine tobacco control activities at the World Health Organisation: report of the committee of experts on tobacco industry documents. Geneva: WHO, 2000, http://www.tobacco.who.int/repository/stp58/who_inquiry.

19 Brugha R, Donoghue $M$, Starling $M$, et al. The Global Fund: managing great expectations. Lancet 2004;364:95-100.

20 International Physicians for the Prevention of Nuclear War. http:// www.ippnw.org/ (accessed 1 Aug 2004).

21 Physicians for Human Rights. http://www. phrusa.org/ laccessed 1 Aug 2004).

22 MEDACT. http://www.medact.org/tbx/pages/ (accessed 1 Aug 2004).

23 Watterson A. Whither lay epidemiology in UK public health policy and practice? Some reflections on occupational and environmental health opportunities. J Public Health Med 1994; 16:270-4.

24 Brown P. Popular epidemiology and toxic waste contamination: lay and professional ways of knowing. J Health Soc Behav 1992;33:267-81.

25 People's Health Assembly Drafting Group. Health in the era of globalization: from victims to protagonists. A discussion paper. Bangalore: People's Health Assembly Secretariat, 2000.

26 Communicable diseases networks. http://europa.eu.int/comm/health/ ph_threats/com/comm_diseases_networks_en.htm (accessed 1 Aug 2004).

27 World Social Forum. http://www.wsfindia.org/anotherworld.php 28 (accessed 1 Aug 2004). 